\title{
Towards an Open SOA for Learning Management
}

\author{
Katrina Leyking', Ralf Angeli², Nils Faltin³, Fabrizio Giorginit, \\ Gunnar Martin ${ }^{1}$,Wolf Siberski, Volker Zimmermann ${ }^{3}$ \\ ${ }^{1}$ Institut für Wirtschaftsinformatik (IWi) im DFKI GmbH, Saarbrücken \\ ${ }^{2} I D S$ Scheer AG, Saarbrücken \\ ${ }^{3} I M C$ AG, Saarbrücken \\ ${ }^{4}$ Giunti Lab S.r.l., Sestri Levante \\ ${ }^{5}$ Forschungszentrum L3S, Leibniz Universität Hannover
}

\section{Motivation}

Looking at today's technologies that are used to build a learning environment reveals a large variety of different software systems and components depending on the learning processes that organisations aim to support. Learning Management Systems (LMS) have established as the core systems in a modern learning environment (Kuechler et al. 2009; Grohmann et al. 2007. They integrate different technologies into a common learning infrastructure. However, given the myriad of learning applications, tools and technologies, organizations struggle to manage the interdependencies between software-supported activities within a modern learning environment. Software products for activities as diverse as learning need analysis, learning design, content authoring, learning itself as well as learning assessment interdependent both conceptually and technically. In addition, the integration of learning software with HR management systems (in corporations) or campus management systems (in higher education) is critical to avoid the isolation of the learning environment within the organization. Instead, learning solutions shall interact with business solutions e.g. for personnel management. When it comes to the business value of learning inter-departmental integration is even more necessary to facilitate the alignment between business needs and learning needs. Businessdriven learning needs are tightly linked to business performance, business processes, products and markets and emerge in the operational business units. Therefore, most recent initiatives promote the integration of business planning and business intelligence software with learning management systems (Leyking und Angeli 2009).

Service-oriented architectures present a viable approach that enables organizations to create an integrated solution of multiple heterogeneous software applications. Instead of expecting one software solution to provide all functionality, an 
organization may pick from diverse software offerings - proprietary or open source, off-the-shelf or custom-tailored, online or offline - and integrate them through service-oriented interfaces. This promotes an evolutionary approach of building learning environments, which are most of the times not built in one step but in multiple stages according to business sizes and needs. Service-orientation caters to the underlying requirement of exchangeable and interoperable software components. Standardized service-oriented interfaces and data exchange interfaces promote an unprecedented degree of interoperability channelled by web protocols. By using standards, the environment can be opened for a flexible exchange of components without having one integrated system. While the learning domain provides important data standards such as IMS-Learning Design, SCORM, and LOM, web service standards are still under way. The future challenge is to make LMSs more and more open and extensible, allowing developers to integrate new learning functionality and vice versa allowing learning functions to be integrated into employee portal or collaboration systems. This paper proposes a generic open SOA approach for learning that has been developed in the EU-co-funded research project PROLIX.

After this introduction, state-of-the-art concepts of service-oriented architecture will be outlined with a specific focus on related work in the domain of learning management (chapter 2). Based on these findings, chapter 3 will review the requirements of the learning management landscape. It prepares the groundwork for the proposed service-oriented architecture for learning as outlined in chapter 4. The paper closes with a conclusion and sketches future research in chapter 5 .

\section{State-of-the-Art and Related Work}

\subsection{Service-oriented Architectures}

In the domain of software architecting, the principle of service-orientation experienced multiple iterations until it manifested itself in the terminology of service-oriented architecture (SOA). Originally coined by Gartner in 1996, SOA has seen a surge of interest expressed both by research communities and industry groups Despite diverse SOA concepts, there is an underlying agreement on the structure of a service-oriented architecture that has been cited and used for illustration purposes throughout literature (Krafzig et al. 2004, S. 62; Dostal 2005, S. 12; Bick und Pawlowski 2006; Masak 2007, S. 101; Heutschi 2007, S. 33; vom Brocke 2008, S. 19): A service-oriented architecture embraces three types of entities. Service providers, service consumers, and service brokers. Service providers offer their capabilities encapsulated as services with well-defined interfaces to be accessed and deployed by service consumers. To make service consumers knowledgeable about available services, service providers either communicate interface specifications bilaterally or publish their service availabilities to a service 
broker who maintains a service registry for potential service customers. Here, services can be searched and discovered before they are deployed by the service consumers. Most recently, the notion of service-oriented architectures has significantly gained attention through the surge of web services and corresponding standards with WSDL and BPEL being the most prominent web service languages. However, service-orientation remains an independent concept that may be supported by new service technologies in the future. Therefore, we propose a conceptual architecture that may be implemented with web services by now or any other interface standards by tomorrow.

\subsection{Service-orientation in the Domain of Learning Management}

The application of service-oriented computing to learning and knowledge management systems - yet in its infancy - has been proposed and promoted by a number of research and industry initiatives. Software providers - both proprietary and open source - have partly responded with attempts of enabling their products in a service-oriented fashion. Also, many ongoing European research projects tackling innovations in the field of technology-enhanced learning use service-orientation as a means of integration, albeit do not put a research focus on it. In correspondence to the general SOA evolution, learning systems build upon a history of related developments concerning component-orientation, XML-based interoperability and most recently grid computing. Thus, reviewing the state-of-the-art of learning service architectures cannot ignore those previous and parallel developments.

Chen (2002) has started the discussion by posing the question on the meaning of web services for web-based education. Whereas the relevance of interoperability and reusability for education components has been one of his major arguments, he has already recognized the challenge of having too many, unstructured and disordered educational web services.

Taking one step back and looking upon the evolution of learning management systems reveals the three generations of monolithic, modular and service-oriented LMS as analyzed by Dagger (2007). In a first step the quest for more interoperability addressed content sharing among monolithic systems by the use of learning object standards (e.g. SCORM, IMS Content Packaging). An initial approach that departed from monolithic concepts is represented by the learning technology systems architecture (LTSA) published by the IEEE learning technology standards committee (Pawlowski \& Adelsberger 2001). Embedded in this standard architecture, a CORBA-based framework - CORBALearn - has been proposed by Anido et al. (2002) to support distributed and interoperable training systems. By using the Common Object Request Broker Architecture (CORBA) they aim towards an early form of a service-oriented architecture. They name their concept an open reference architecture consisting of domain-specific service definitions. The ultimate aims are component (i.e. service) reuse and interoperability (Anido et al 2002). Another initiative has been started by Eduforge, a virtual community on open 
education technology in New Zealand. The Open Learning Suite (OLS) has been promoted by Bailetti $(2004 ; 2005)$ as a "service-oriented architecture for custom learning environment using existing open source applications and systems". However, further activities have been discontinued for the sake of universal standardization efforts. To face the challenge of handling multiple learning service definition initiatives as predicted by Chen, the standardization bodies IMS Global Learning Consortium (IMS-GLC) and IEEE Learning Technology Standards Committee (IEEE-LTSC) have been setting up service frameworks to provide guidance for service-oriented learning systems. Whereas IEEE refrains from a SOA-specific framework and offers a component-based learning technology systems architecture (LTSA) instead, IMS deliberately chose to focus on web service technology. It builds upon the work on the British-Australian eLearning Framework (ELF) initiated by JISC and DEST, which have joined the IMS working group by now (Wilson et al 2004). IMS-GLC has developed and published the IMS General Web Services Specification that "promotes interoperability for web service based specification implementations on different software and vendor platforms. The General Web Services Base Profile addresses interoperability in the application layer, in particular, the description of behaviours exposed via Web Services" (Smythe 2007).

The term service-oriented learning architecture (SOLA) has initially been introduced by Clark and Booth (2006). Their approach builds upon the JISC elearning framework and basically differentiates SOLA from SOA in the objects of alignment. Whereas a SOA is aligned with business processes, SOLA shall be aligned with teaching and learning processes. According to the authors another distinguishing feature of SOLA is that it addresses only the business of teaching within universities and not within companies. In line with these two distinctions, they propose a definition that is analogous to a classic SOA definition except for a strong focus on the educational domain: "Service-oriented Learning Architecture is an IT-strategy that organizes the discrete functions contained in an educational network into interoperable, standards-based services that can be combined and reused quickly to meet teaching, learning, research, and administration needs" (Clark und Booth 2006b, S. 2). They claim that number and diversity of services within SOLA would be very significant due to the involvement of externally provided services. SOLAs would "tend to federate more freely and over a wider area than a SOA" (Clark und Booth 2006b, S. 5). Clark and Booth further state that the challenge will constitute in managing the diversity of web services, web applications and content while supporting structures, procedures and aims of a university, service-oriented LMS in a homogeneous manner.

The term "service-oriented learning environment" as it is used by Vercoulen (2005) emphasizes that future LMSs will not exist as an independent entity but shall be integrated into service-oriented organizational and technical architectures. Dagger (2007) explicitly motivated the need for flexible learning services by the failure of traditional monolithic Learning Management Systems (LMS) to keep pace with advances in internet technologies and social interactions online. He joins 
Clark and Booth's call for federating services, for various levels of interoperability and for service composition environments.

In the German-speaking information systems community, Westerkamp and Vossen (2003) have pioneered service-oriented learning systems especially for higher education. Within the LearnServe project they developed a prototypical service-oriented e-learning environment for tertiary education (Westerkamp 2006). It follows the vision of distributed e-learning solutions allowing providers to sell access to individual learning content and learning services. Based on the IEEE LTSA standard LearnServe offers reasonable services for reuse in e-learning which can interact and be composed to processes.

Although open source and proprietary vendors of LMS slowly provide hooks to tie third-party software into the LMS (CIO Magazine 2003), most web-based educational systems are still developed from scratch. Despite a multitude of singular approaches to apply service-orientation to the domain of learning and knowledge management there is not yet drawn a link to ongoing transformation of business information systems into business services. Corporate purposes of learning and knowledge services are faintly indicated but not elaborated upon in any account. However, limiting a SOLA to the alignment of learning and teaching processes in academic institutions appears narrow-minded. Considering the fact that knowledge and learning management has evolved to a major instrument in corporate organizations closely interlinked with business processes, developing serviceoriented learning architectures cannot be decoupled from the adoption of enterprise wide service-oriented infrastructures. Business information systems such as Human Resource Management systems or Planning Systems ask for seamless integration with learning management systems based on services (Bick and Pawlowski 2006, S. 276).

\section{Learning Technology Landscape and Requirements}

The learning technology landscape encompasses a broad range of systems for managing training records to distributing courses over the Internet and offering features for online collaboration. Learner self-service (e.g., self-registration on instructor-led training), training workflow (e.g., user notification, manager approval, wait-list management), the provision of online learning (e.g., ComputerBased Training), online assessment, management of continuous professional education, collaborative learning (e.g., application sharing, discussion threads), and training resource management (e.g., instructors, facilities, equipment), are dimensions of Learning Management Systems. Examples of well-known LMS products are Blackboard, Clix, GeoLearning, Learn.com, Plateau, Saba, SumTotal, WebCT. Most diffused open-source LMS are Moodle and Sakai. In essence, an LMS is software for planning, delivering, and managing learning events within an organization, including online, virtual classroom, and instructor-led courses. 
The prevalence of LMS in both corporate and tertiary educational practice parallels the predominance of ERP systems in business operations as examined for a large number of European institutions (e.g. Paulsen 2003). Arising from so-called course management systems and emerged to web-based and didactically aware e-learning systems, LMS primarily focus on the management of learning and training processes, distributing the learning content, supporting the learning process, and serving as a shared communication point and interface between learners and teachers (Helic 2006). Using an LMS, the organisation collects data to enable decisions in order to create better learning, to fulfil compliance needs and to manage an efficient education and training business. Using learning objects as a central artifact LMS provides unparalleled structured and systematic support to a teacher and enables him to facilitate learning among his students (Kraemer et al., 2007). Figure 1 illustrates integral parts of an LMS:

- Content management components enable an organisation to manage a large scale of different learning objects, to reuse and repurpose them in different courses or learning settings. It delivers and manages instructor-led synchronous and asynchronous online training based on learning object methodology. This functionality may also be provided by stand-alone Learning content management systems (LCMS), examples of which are the eXact Packager, Lectora, ToolBook and Eedo.

- Process management allows the organisation to manage the workflows and business processes such as booking of courses, notifications to inform learners and teachers about events or learning activities, setting up a learning process or "syllabus" and run training programs.

- When it comes to instructional design, a wide range of tools is available for sharing or creating content. Learning design tools allow learning activities to be specified according to instructional design theories and to specific a syllabus with activities of learners and tutors.

- Virtual classroom tools support activities of synchronous learning like sharing of workspaces and resources as well as live discussions between different participants.

- Authoring tools allow to create and to publish content using standard technology to integrate the result of the creation process into the plat-forms (e.g. SCORM).

- Test and Assessment systems allow exercises to be created and to be integrated into tests and tests to be run in order to proof the knowledge and people to be certified for a specific knowledge level.

From an organizational perspective, many additional components may extend a learning environment.

- Training and event management systems support the management of on-site training events, such as administrating participants, waiting lists, confirmation lists and cancellation of class participations. 
- Resource management systems help to optimize the resources needed to execute training and education, such as room administration, reservation and booking of trainer resources, ensuring, that all training re-sources such as projectors and overhead are available etc.

- Skill and competency management systems facilitate the planning and storing of current and planned skills of employees as well as skill and competency profiles for job roles. They support a skill-gap-analysis in order to create a competency and training plan for people according to the course offering in the LMS.

- Performance management systems help to track the learning outcome of people through courses, link the training with evaluations and 360 degree feed-back in order to create content that leads to higher performance of an employee.

Collaborative, social and informal learning plays an increasingly important role within a virtual learning environment. These tools may be stand-alone web-based applications in the web 2.0, integrated through mash-ups or integral part of an LMS.

- Wikis, Blogs, Search Functionality, RSS-Feeds etc. support learners sharing and creating knowledge, either within a course (formal learning) or in a self-organised way (informal learning).

- Social Network systems and open content platforms support the exchange of information, knowledge and learning objects, interlink people around content and create networks of common interest.

When integrating LCMS, LMS, CMS solutions, HR systems or Digital Repositories the integration should be made easy by the newly available standards and services, as well as act as an evidence of the real adherence and openness of the engaged systems. Granting a none "Locked in" status to all the content produced and managed by the new integrated setup based on the SOA concept, should be clearly a unique benefit for the end user. In addition, the SOA approach allows to combine the use of discrete but complementary tools and web services such as blogs, wikis, podcasting and other social software to support the creation of ad-hoc learning communities, helping to make e-learning far more personal, social, and flexible. Such a service-oriented approach towards learning management creates an economic advantage also for organizations by improving "speed to capability" or shortening the amount of time it takes to get workers up to speed on new products and processes. 


\section{The Learning Service Architecture}

\subsection{Layers of the Learning Service Architecture}

The SOA for Learning opens existing learning applications over standardized service interfaces for data and functionality access, supporting cross-application business and learning processes. A multi-layer structuring facilitates flexible composition of learning management services and lightweight configuration of user interfaces facilitated by an Enterprise Service Bus and service-oriented portal technologies.

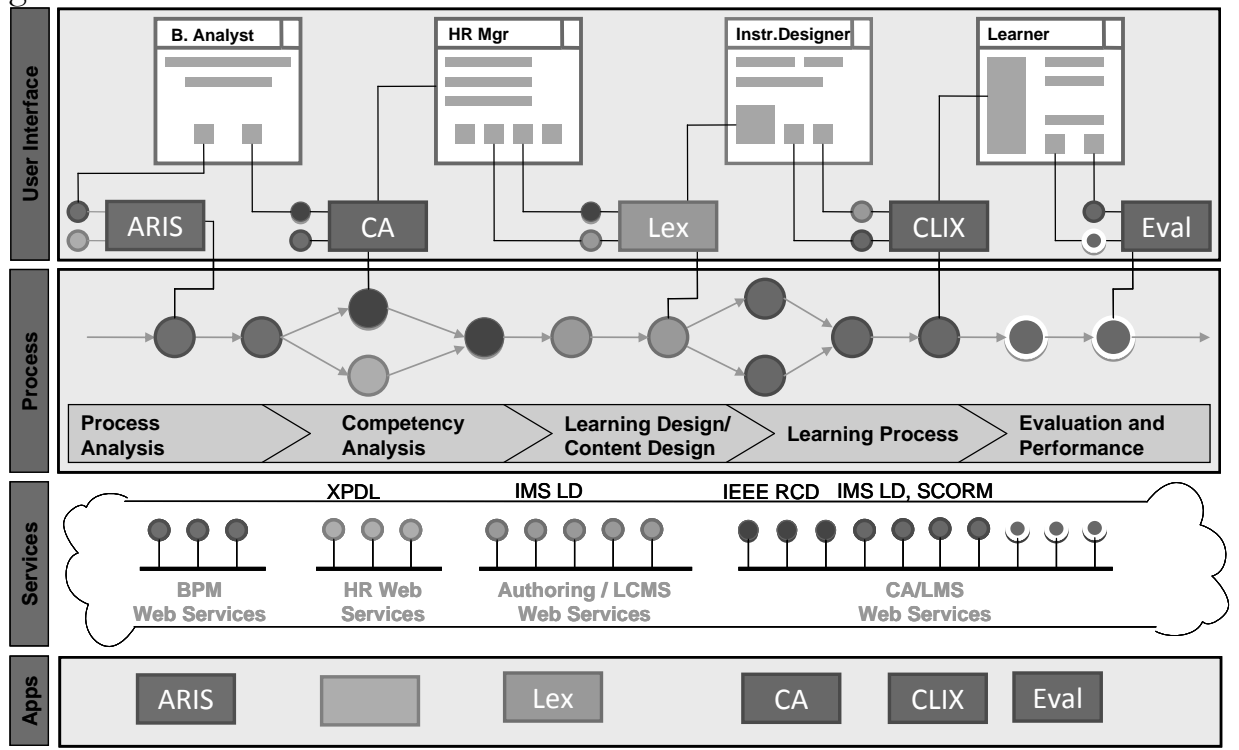

Figure 1: SOA For Learning Architecture

The ESB allows processes to be specified through service composition. Since learning management processes are rarely fully automated, services include human tasks conducted by participating persons. In order to realize this functionality, the ESB is coupled with a workflow engine. Workflows deploy semi-automated processes across applications, but they can also be used to specify reactions to events in the system. For example, the event of successfully completing a test can trigger the update of a learner profile in another system.

On the user interface level, a component-based approach is used. Applications provide aspects of their user-level functionality as gadgets, in the same fashion as they offer system-level features as services. These gadgets are used to compose custom interfaces according to specific tasks. For example, an HR specialist's user interface might combine gadgets from a human resource application, a competency management system, and an LMCS. 
The combination of service abstractions on the application level, composable gadgets on the user interface level, and workflows as glue ensures a seamless integration of different applications, while maintaining a lose coupling between the involved software services.

\subsection{Learning Management Services}

By defining learning management services conceptually, this section presents a reference blueprint for providing service-oriented access to software services in a learning management environment. As the following section will elaborate, those singular services may again be composed into complex learning workflows.

From a mechanical point of view, learning can be understood as a means to close a competency gap, i.e. a discrepancy between required and provided competencies and competency levels of a person being faced with certain tasks or taking certain roles. In order to identify the gap and close it, different information artifacts have to be created, read, updated, or deleted (data services). Additionally they must be matched, combined and processed (task services). The following section specifies those services on a conceptual level that provides a requirements basis for actual web service implementations.

We differentiate five groups of services: competency management services, learning resources management services, learning execution management services and performance management services.

Competency management services are concerned with the determination of competency gaps, i.e. it covers the management of both required and provided competencies. The required competencies usually refer to tasks, roles, positions or jobs and therefore have different sources, like business process descriptions, career plans, job descriptions or compliance regulations. Data services for the management of required competencies have to provide the possibility to create and manipulate information about competencies, artefacts they are required for and the relations between them.

The provided competencies refer to the actual knowledge and skills of individuals. Data services for the management of such competencies would also have to provide the possibility create and manipulate information about the competencies as well as the persons providing them and the relations between them.

Business information about tasks, positions or persons are often kept in systems not primarily concerned with competency management (e.g. business process management software, ERP systems). In such cases it can be enough to handle and store only references to those pieces of information and not require the competency management service to deal with the whole range of data. Sometimes this might even be required due to privacy concerns.

The competency gap analysis compares required and provided competencies (matching). This is supported by a task service that determines the suitability of a person for a role, and returns the result of the comparison. This result, the infor- 
mation about the competency gap, can then be used to select suitable training measures using the matching service.

The supply side for filling a competency gap is formed by learning resources. Learning resources management services are hereby concerned with the creation, description and provision of such learning resources and information about them. These services provide the possibility to create or store a learning resource and its meta data as well as to update and delete the information.

Since each learning resource may address different competencies and competency levels, a full-fledged learning resources management also has to provide a way to determine which resources can be used to close a given competency gap. The respective task service would have to accept information about the competency gap as input and reply with a set of references to matching learning resources. The returned result would indicate if there is no learning resource readily available for certain parts of the competency gap. The learning management system might for such cases also provide a service for requesting a new learning resource which would accept a description of the competency gap to be addressed.

If the person to be trained and the learning resources to be used are known, the learning process can be started. The execution of the learning process is handled by the learning execution management services. Corresponding data services have to provide the possibility to create a learning process and configure it with information about the person to be trained and the resources to be used. There might also be services to query or manipulate the status of learning process execution and to restart, stop or delete a learning process instance.

Checking the outcome of learning, i.e. determining if the competency gap could be closed, is the objective of performance management services. This can be done with various means, one of them being a test related to the courses taken and learning resources consumed by a person during learning process execution. Corresponding data services would have to provide the possibility to create and define such tests and information about which learning resources are covered by them. Task services allow tests to be instantiated and administered for certain persons in reference to the learning resources they have consumed or the competencies they have to be tested in. The test results could also be made accessible through serviced.

Besides the learning outcome evaluation can be concerned with business or business process performance evaluation. These functions are usually not associated directly with learning management. They may, however, indicate performance problems in an organization which are related to missing competencies. Through the means of services, performance data may be exchanged between performance management and learning management systems. 


\subsection{Service-Oriented Learning Management Process}

Having these service specifications defined and available as implemented software services, learning management workflows can be composed on demand. To exemplify the flexibility achieved by this approach, we present a workflow example for "personnel development". It aims at assembling a competency plan for a set of employees geared towards specific competency requirements. As input it expects information about the as-is competencies of the employees and the to-be competencies defined by the roles. It produces updated as-is competency profiles of the employees as output. The detailed description of the workflow reads as follows:

The workflow starts with an HR manager creating a so-called competency plan that contains a set of planned (or already existing) assignments of persons to roles. A training specialist then selects appropriate learning units to cover the competency gaps resulting from the specified role assignments. The learning management system helps the training specialist finding and suggesting suitable learning units against to close the gaps. Each time the training expert adds a learning unit to the competency plan, the remaining gap is recomputed, and can again be inspected to determine the next learning unit. In case the gap cannot be covered by existing learning units, new learning templates and learning units are requested and created, including their annotation with learning prerequisites and objectives. The final competency plan is reviewed by the HR manager and possibly revised. If the competency plan is accepted, the training expert creates course instances based on the suggested learning units. Employees listed in the competency plan are then booked on these courses, based on their individual competency gaps. Finally the employees participate in the learning activities and are tested with respect to the acquired knowledge.

\section{Conclusion and Outlook}

The architecture proposed in this paper presents a conceptual blueprint for open learning service architecture that shall guide the development of learning service standards. The objective is to promote the notion of open interfaces among learning technology providers and related fields. Eventually, this shall empower organizations and end users to configure their learning environments based on their specific needs and constraints. This paper has been written in the context of the PROLIX project that is co-funded by the European Union's Sixth Framework Program "Information Society Technologies" (proposal no. 027905). The authors sincerely acknowledge the valuable contributions of their project partners, especially the industry test beds. Their constructive feedback re-confirmed the very need for more flexible integration among learning management software and influenced the work on the Open SOA for learning decisively. With the completion of the project, there will be a reference implementation of the architec- 
ture blueprint that prototypically demonstrates internal workings and organizational benefits.

\section{References}

Anido L, Caeiro M, Rodriguez J, Santus J (2002) Architecting CORBA-based frameworks to support distributed and interoperable training systems in large enterprises. In: Proceedings of the 11th IEEE international workshop on enabling technologies: Infrastructure for collaborative enterprises (WETICE'02).

Bailetti T, Weiss M, McInnis G (2004) A service-oriented architecture for creating customized learning environments. http://www.scs.carleton.ca/ weiss / papers/swig04.pdf.

Bailetti T, Weiss M, McInnis G (2005) An open platform for customized learning environments. In: Proceedings of the International Conference on Management of Technology (IAMOT).

Bick M, Pawlowski J (2006) Interface standards: Integration of learning and business information systems. In: Ehlers UD, Pawlowski J (Hrsg) Handbook on Quality and Standardisation in E-Learning. Springer, Berlin.

Chen W (2002) Web Services - What do they mean to web-based education? In: Proceedings of the IEEE International Conference on Computers in Education (ICCE'02), Auckland, New Zealand.

CIO Magazine (2003) E-Learning hits web services books. http://www.infoworld. com/article /03/02/17/PLelearn_1.html.

Clark B, Booth A (2006) The WAFFLE bus: A model for a service-oriented learning architecture. In: Whitelock D, Wheeler S (Hrsg) The next generation. Research Proceedings of the 13th Association for Learning Technology Conference (ALT-C 2006), Edinburgh.

Dagger D (2007) Service oriented eLearning platforms: From monolithic systems to flexible services, IEEE Internet Computing, 11(3):28-35.

Dostal W (2005) Service-orientierte Architekturen mit Web Services. Spektrum Akademischer Verlag, Heidelberg.

Grohmann G, Kraemer W, Milius F, Zimmermann V (2007) Modellbasiertes Curriculum-Design für Learning Management Systeme: Ein Integrationsansatz auf Basis von ARIS und IMS Learning Design. In: Oberweis, A. et. al. (Hrsg.): Tagungsband 8. Internationale Konferenz Wirtschaftsinformatik, Karlsruhe. 
Helic, D (2006) A Didactics-Aware Approach to Management of Learning Scenarios in E-Learning Systems. Graz University of Technology.

Kraemer W., Milius F, Zimmermann V (2007) Von WINFO-Line zum Corporate Learning Management - Nachhaltiger Transfer wissenschaftlicher Konzepte in wettbewerbsfähige Produkte. IM Information Management 20. Special Edition: 50-67.

Krafzig D, Banke K, Slama D (2004) Enterprise SOA: Service-Oriented Architecture Best Practices. Prentice Hall, Upper Saddle River.

Kuechler T, Thissen D, Zimmermann V (2009) Into the great wide open: Responsive Learning Environments for Personalised Learning. In: O’Donoghue J (Hrsg): Technology Supported Environment for Personalised Learning: Methods and Case Studies. IGI Global, London.

Leyking K, Angeli R (2009) Model-based, Competency-Oriented Business Process Analysis. Enterprise Modelling and Information Systems Architecture Journal, 4(1):14-25.

Masak, D (2007) SOA? Serviceorientierung in Business und Software. Springer, Berlin.

Paulsen MF (2003) Experiences with Learning Management Systems in 113 European Institutions. Educational Technology \& Society, 6(4):134-148.

Pawlowski JM, Adelsberger HH (2001) Standardisierung von Lerntechnologien. Wirtschaftsinformatik, 43(1):57-68.

Smythe C (2007) IMS General Web Services Base Profile: Final specification, IMS Global Learning Consortium. http://www.imsglobal.org/gws/gwsv1p0 /imsgws_baseProfv1p0.html.

Vercoulen F (2005): Toward service-oriented learning environments. http://www.alt.ac.uk/altc2005/timetable/files/630/ALTC_Service\%20oriented\%20learning\%20environment_050905.ppt.

Vom Brocke J (2008) Serviceorientierte Architekturen: Management und Controlling von Geschäftsprozessen. PhD Thesis, Westfälische WilhelmsUniversität Muenster. Vahlen, München.

Vossen G, Westerkamp P (2003) E-learning as a web service. In: Proceedings 7th International Conference on Database Engineering and Applications (IDEAS), Hong Kong.

Westerkamp P (2006): Flexible e-learning platforms: A service-oriented approach. Logos, Berlin. 
Wilson S, Blinco K, Rehak D (2004) Service-oriented frameworks: Modeling the infrastructure for the next generation elearning Systems. http://www.jisc. ac.uk/uploaded_documents/AltilabServiceOrientedFrameworks.pdf. 